\title{
Design and Development of Experimental Based Phase Modulated Model Predictive Control for Torque Ripple Reduction of MMC Fed BLDC Motor
}

\author{
Rahul Jaiswal*, Anshul Agarwal**, Richa Negi* and Abhishek Vikram*** \\ *Electrical Engineering Department, MNNIT Allahabad, Prayagraj, India \\ **Electrical Engineering Department, NIT Delhi, New Delhi, India \\ ***Anchor Semiconductor, Santa Clara, USA \\ Corresponding author : ree1651@mnnit.ac.in
}

\begin{abstract}
This article represents the torque ripple performance of modular multilevel converter (MMC) fed brushless dc (BLDC) motor using different current control technique. For reducing the ripple current in BLDC motor, a phase-modulated model predictive control (PMMPC) technique has been proposed. The stator ripple current is almost negligible using PMMPC. This PMMPC current control method is a significant minimization of torque ripple in BLDC motor. A comparative torque ripple behaviour of MMC fed BLDC motor has been done using phase-modulated model predictive control, model predictive control (MPC) and proportional integral (PI) control at different switching frequency. It has been observed that a PMMPC current control technique is more efficient as compared to the MPC as well as PI current control technique. It has also been observed that the torque ripple performance is improved while using PMMPC as compared to the MPC and PI controller. Simulation results have been verified with the help of experimental result and these results are obtained in good agreement to the simulated results.
\end{abstract}

Keywords:Phase modulated model predictive control (PMMPC); Torque ripple; Modular multilevel converter (MMC); Brushless DC (BLDC) moto

\section{INTRODUCTION}

The Brushless DC (BLDC) motor has been implemented in various application due to its numerous advantages likes, higher efficiency, steady-state response, high reliability, small size, and low-cost maintenance etc., [Cui, C. et al., 2015; Shao, J., 2006]. Nowadays, BLDC motor is very demanding due to electric vehicle market. This motor has following characteristics like quasi rectangular current waveforms, trapezoidal electromotive force, as shown in figure 1 . The armature current is not commutated immediately because of its armature winding inductance. This armature winding is responsible for ripple in armature current which leads the torque ripple. This ripple is major downside of BLDC motor, as result deteriorate the performance, generates the noise, oscillation and vibration [Kim, H. et al., 2015]. Improvement of execution of this motor is very challenging for researchers nowadays. The several techniques are implemented to resolve this problem in BLDC motor. Many researchers have been improved the performance via modification of circuit, different control technique etc. A different hybrid converter circuit [Viswanathan, V. et al., 2015] has been used to improve the torque ripple performance. In this technique, a dc-dc converter is connected with different converter for controlling the speed by regulating the supply voltage, which leads to the suppression of ripple current. A buck converter is used with a modified converter topology to improve torque ripple [Krishnan, G. et al., 2014]. For reducing the ripple current in BLDC motor, SEPIC converter is used with hybrid circuit topology for getting desired dc-link voltage [Viswanathan, V. et al., 2018]. A multilevel converter is used in place of 2 level converter for getting the better response of BLDC motor. A cascaded $\mathrm{H}$ bridge converter is used 
to get improved performance of BLDC motor [Doss, M. A. et al., 2013]. A hybrid Sic based neutral point clamp (NPC) multilevel converter is used with SEPIC for getting the desired response [Viswanathan, V. et al., 2017]. Performance and behaviour of BLDC motor are improved

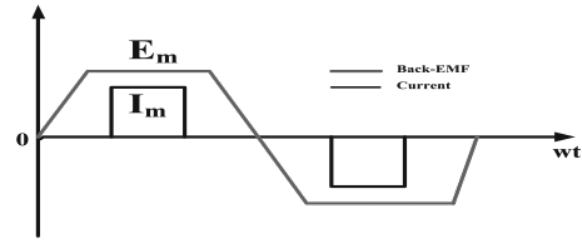

Figure 1. Ideal case of BLDC motor

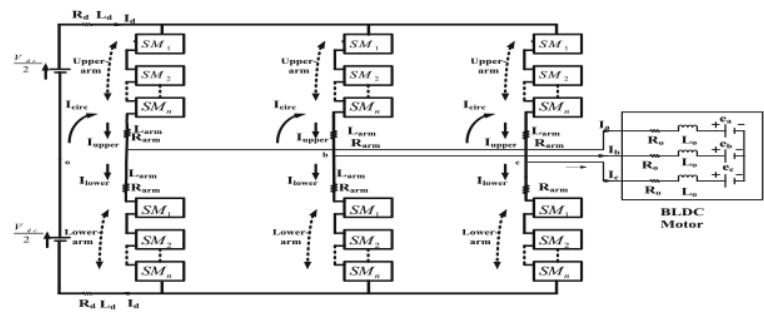

Figure 2. MMC fed BLDC motor

using these modified converters. A different control technology has also been proposed in recent years for improving the torque ripple performance of BLDC motor. Several PWM method has been used to reduce ripple current likes PWM chopping, space vector modulation (SVM), and overlapping method [Baszynski, M. et al., 2018; Lad, C. K. et al., 2018]. The duty ratio is controlled by controlling the PWM algorithm to enhance the performance of BLDC motor [Lee, Y., 2019]. A direct torque control technique is applied to remove the torque ripple. In this method, rotor position error has been reduced using a hall sensor which leads to the improve the performance of torque ripple [Ozturk, S. B. et al., 2011]. Nowadays, Current control strategy is very beneficial for different application [ Irum, M. et al., 2020; Sarkar, P. et al., 2020]. So these current control strategies have also been proposed for improving ripple current. A dead-beat current controller is implemented to control the torque ripple. In this method, equate the slope of incoming and outgoing stator current for reducing the torque ripple. [Song, J.H. et al., 2004]. Adaptive feedback linearization control technique is reported for control the torque ripple and also very helpful to control the motor parameter variation like stator inductance and resistance [ Boroujeni, M.S. et al., 2017]. A fuzzy control method is implemented to control the ripple current for improving the performance of the BLDC motor [Yaya, S. et al., 2009]. A hybrid PI fuzzy-based control technique is reported for controlling the speed and commutated torque ripple [Manikandan, R.et al., 2013]. Nowadays, a predictive control strategy has been studied.

This technique is beneficial to increase the performance of any system. A useful result has been developed with multilevel converter using model predictive control strategy [Liu, X. et al., 2019; Vasiladiotis, M. et al., 2019]. In this control strategy, an optimal switching state behaviour has been observed from finite possible switching state variable, which is generated by a multilevel converter and applied for next sampling period [Rodriguez-Bernuz, J. et al., 2020]. A model predictive control strategy has been employed with multilevel converter. This control technique is a very advanced and efficient technique to be used in drives system.

In this paper, a novel phase-modulated model predictive control technique for reducing the torque ripple of MMC fed BLDC motor has been proposed. A phase-modulated triangular carrier waveform analysis has shown. The torque ripple analysis has been done using PMMPC, MPC and PI current controller. An effect of torque ripple has also been done at different switching frequency. A comparative study of torque ripple and stator current of BLDC motor Has also been shown using above mention current control technique at different switching frequency. Experimental analysis has also done to validate the simulation result. 


\section{MATHEMATICAL ANALYSIS OF MODULAR MULTILEVEL CONVERTER (MMC) FED BLDC MOTOR}

A typical BLDC motor coupled with half-bridge submodule modular multilevel converter, as mentioned in figure 2. The modular multilevel converter is one of the efficient converters as compared to other multilevel converters due to the presence of submodules. These submodules reduced the cost of converter as well as reduced the size of converter [Lei, M. et al., 2020]. There are different types of submodule used in MMC such as half-bridge submodule, full-bridge submodule, flying capacitance, neutral point clamp, etc. The half-bridge submodule is efficient as compared to other submodules [Jaiswal, R. et al., 2019; Li, J. et al., 2020].

By applying KVL in a given circuit,

$$
\begin{aligned}
& \frac{V_{d}}{2}=I_{d} r_{d}+L_{d} \frac{d I_{d}}{d t}=V_{u}+I_{u} r_{m}+L_{m} \frac{d I_{u}}{d t}+I_{a_{o}} r_{c}+L_{o} \frac{d I_{a}}{d t}+e_{a} \\
& \frac{V_{d}}{2}=I_{d} r_{d}+L_{d} \frac{d I_{d}}{d t}=V_{1}+I_{1} r_{m}+L_{m} \frac{d I_{1}}{d t}+I_{a} r_{o}-L_{o} \frac{d I_{a}}{d t}-e_{a} \\
& \left.\begin{array}{l}
V_{t}=V_{u}-V_{1} \\
I_{a}=I_{u}-I_{1}
\end{array}\right) \\
& \frac{1}{\left(\mathrm{~L}_{\mathrm{m}}+2 \mathrm{~L}_{\mathrm{o}}\right)}\left[\left(\mathrm{V}_{1}-\mathrm{V}_{\mathrm{u}}\right)-\left(\mathrm{r}_{\mathrm{m}}+2 \mathrm{r}_{\mathrm{o}}\right) \mathrm{I}_{\mathrm{a}}-2 \mathrm{e}_{\mathrm{a}}\right]=\frac{\mathrm{dI}}{\mathrm{dt}}
\end{aligned}
$$

Similarly, obtained phase current $\mathrm{b}$ and $\mathrm{c}$

$$
\mathrm{T}_{\mathrm{a}}=\frac{1}{\mathrm{~W}_{\mathrm{m}}}\left(\mathrm{e}_{\mathrm{a}} \mathrm{I}_{\mathrm{a}}+\mathrm{e}_{\mathrm{b}} \mathrm{I}_{\mathrm{b}}+\mathrm{e}_{\mathrm{c}} \mathrm{I}\right)
$$

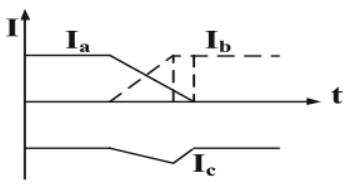

(a)

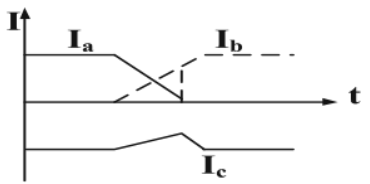

(b)

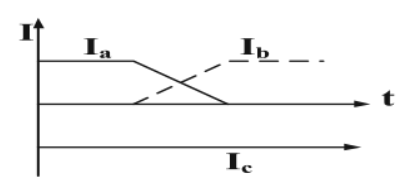

(c)

Figure 3 stator current analysis during different case

In [Viswanathan, V. et al., 2017], the torque ripple analysis has been observed. There are different condition to avoid the torque ripple in BLDC motor. As, seen in figure 3, the Spikes and dips are available in current waveform, which is responsible for ripple. For reducing the spikes and dips in BLDC motor, the stator ripple current has to be reduced. The MPC technique is one of the advanced methods to overcome the ripple current in BLDC motor by making the Vdc close to equal to back emf. 


\section{MODEL PREDICTIVE CONTROL}

Due to the inclusion of nonlinearity and system constraints, the model predictive control technique is one of the effective methods for power converter [Dekka, A. et al., 2019]. As compared to other control techniques, the MPC is better steady-state response and lower ripple. In this technique, future behaviour of system predicted by converting in a discrete system [Abdelkader, L., et al., 2019]. The cost function term is used to optimized the error by comparing the present value and past value and applied for next sampling state. In the case of power converter, the optimized switching state has been obtained from finite switching state and applied for next sampling state [Zarei, M. E. et al., 2020]. Cost function is denoted by $\mathbf{J}$

$$
\mathrm{J}=\mathrm{i}(\mathrm{k}+\mathrm{l})-\mathrm{i}^{*}(\mathrm{k}+1)
$$

Where $\mathrm{i}(\mathrm{k}+\mathrm{l})$ is predicted value and $\mathrm{i}^{*}(\mathrm{k}+\mathrm{l})$ is the reference value. Discrete analysis of MMC: By applying desecrate system in (4)

$$
\begin{gathered}
\frac{\mathrm{dI}}{\mathrm{dt}}=\frac{\mathrm{I}(\mathrm{k})-\mathrm{I}(\mathrm{K}-1)}{\mathrm{T}_{\mathrm{s}}} \\
\mathrm{I}_{\mathrm{a}}(\mathrm{k})=\frac{\mathrm{T}_{\mathrm{s}}}{\left(\mathrm{L}_{\mathrm{m}}+2 \mathrm{~L}_{\mathrm{o}}\right)}\left[\left(\mathrm{V}_{\mathrm{l}}(\mathrm{k}-1)-\mathrm{V}_{\mathrm{u}}(\mathrm{k}-1)-2 \mathrm{e}_{\mathrm{a}}(\mathrm{k}-1)\right]+\mathrm{I}_{\mathrm{a}}(\mathrm{k}-1)\left[1-\left(\mathrm{r}_{\mathrm{m}}+2 \mathrm{r}_{\mathrm{o}}\right) \frac{\mathrm{T}_{\mathrm{s}}}{\left(\mathrm{L}_{\mathrm{m}}+2 \mathrm{~L}_{\mathrm{o}}\right)}\right]\right. \\
\mathrm{I}_{\mathrm{a}}(\mathrm{k}+1)=\frac{\mathrm{T}_{\mathrm{s}}}{\left(\mathrm{L}_{\mathrm{m}}+2 \mathrm{~L}_{\mathrm{o}}\right)}\left[\left(\mathrm{V}_{\mathrm{l}}(\mathrm{k})-\mathrm{V}_{\mathrm{u}}(\mathrm{k})-2 \mathrm{e}_{\mathrm{a}}(\mathrm{k})\right]+\mathrm{I}_{\mathrm{a}}(\mathrm{k})\right. \\
\end{gathered}
$$

The model predictive control has some advantages, but there are some disadvantages too, which affects the performance converter and other systems. These disadvantages are nonlinearity, variable switching frequency, dealy and so on [Dekka, A. et al., 2019]. These disadvantages affect the output performance of power converter as well as generate the torque ripple in the BLDC motor. For improving the ripple current, the new phase-modulated model
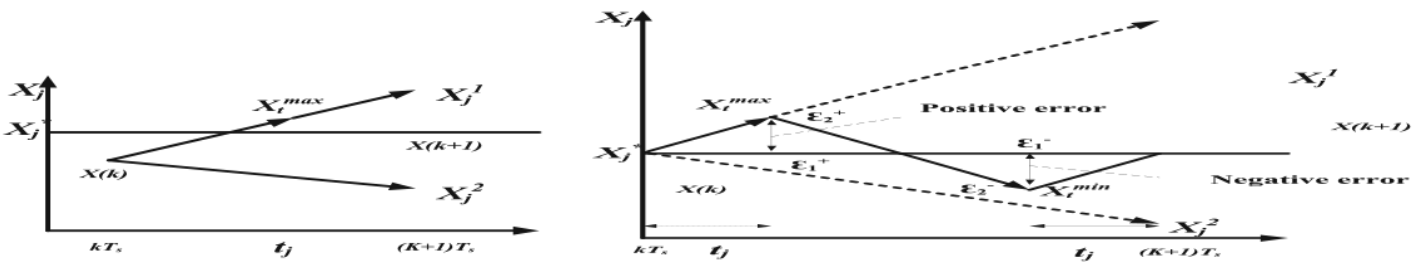

Figure 4. Two state vector trajectory Figure 5. Two sate vector analysis of triangular carrier predictive control technique has been proposed, which improves the torque ripple performance

\section{PROPOSED PHASE-MODULATED MODEL PREDICTIVE CONTROL (PMMPC)}

The proposed method defined the two-switching vector state to an optimized cost function [Mahmoudi, $\mathrm{H}$. et al., 2017; Tarisciotti, L. et al., 2014]. These vector state used to predict the future value of particular switching state from all possible state and implemented to the converter for next sampling state. This cost function is calculated by comparing the present and future value for both vector state and choose the optimized value. As depicted in figure 4 , the two-state switching vector of the converter $\left(x_{j}\right) . x_{j}^{*}$ is the reference value of $x_{j}$ and $x_{j}(k+1)$ is the future value of $x_{j}(k)$. The $x_{j} 1$ and $x j 2$ is the switching state vector of state one and two, respectively. These state vector should lie close to the reference value $x_{j}^{*}\left(x_{j}^{1} \leq x^{*} \geq x_{j}^{2}\right.$. The main target is to make $x_{j}(k)$ close to reference value at some instant of time during every sampling time. This time is known as switching time between 
state vector 1 and state vector 2. The exact value of switching time can find utilizing duty cycle.For reduce the ripple current in BLDC motor, a new switching strategy has been developed. In this case, a triangular carrier waveform is used for getting proper output performance. As depicted in figure 5, triangular waveform rises to a maximum value $\left(\mathrm{xt}^{\max }\right)$ during state vector 1 and fall back toward the reference value during the state vector condition 2 at the end of sampling period. Moreover, the carrier wave fell beyond the reference value and reach the minimum value $\left(\mathrm{xt}^{\mathrm{min}}\right)$.

The error has been calculated by the difference between the reference value $\left(\varepsilon_{1}^{+}\right)$and maximum value $\left(\varepsilon_{2}^{+}\right)$. This error is known as positive error $\left(\varepsilon_{1}{ }^{+}-\varepsilon_{2}+=x_{j}{ }^{*}-x \operatorname{tmax}\right)$. Similarly, the error has been calculated when the state fell during state vector condition 2 . This error is known as a negative error $\left(\varepsilon_{1}-\varepsilon_{2}-=x_{j}^{*}-x t m i n\right)$. These positive and negative errors almost equal and they are cancelled out, which leads to output waveform close to a reference value. Similarly, phase shift PWM modulation is used to analysis with the help of two state vector switching condition. In this case, each triangular waveform is shifted by (360/Ø) degree to generate the gate signal, which is applied in the converter. The triangular waveform is chosen based on the number of submodules used in MMC.

\section{RESULTS AND DISCUSSION}

The torque ripple suppression analysis of MMC fed BLDC motor has been studied with the help of different current control strategy. All the analysis has been done MATLAB/Simulink. The BLDC motor stator resistance and inductance is $2.8750 \Omega$ and $8.50 \mathrm{mH}$. The rated torque and speed are $2.5 \mathrm{Nm}$ and $800 \mathrm{r} / \mathrm{min}$. The flux linkage established by magnets is $0.1750 \mathrm{~V}$. s. These BLDC motor parameters is used to analysis the performance. Comparative performance of phase-modulated model predictive control (PMMPC), model predictive control (MPC) and proportion integral (PI) control technique has analysed. The torque ripple and stator current of BLDC motor has been shown at switching frequency $2 \mathrm{kHz}, 4 \mathrm{kHz}, 8 \mathrm{kHz}$, as seen in figure 6 , figure 7 and figure 8 . It has been noticed that the torque ripple is 36\%, 48\% and 69\% for PMMPC, MPC and PI controller respectively, at switching frequency $2 \mathrm{kHz}$. If the switching frequency increases, then a large amount of torque ripple will reduce due to reduction of power loss in MMC circuit. Similarly, the torque ripple is $29 \%, 42 \%$ and $63 \%$ for PMMPC, MPC and PI controller respectively at switching frequency $4 \mathrm{kHz}$. The torque ripple is $22 \%, 27 \%$ and $46 \%$ for PMMPC, MPC and PI controller at switching frequency at $8 \mathrm{kHz}$. The overall comparisons of current controller, PMMPC has best torque ripple performance as compared to other control technique.
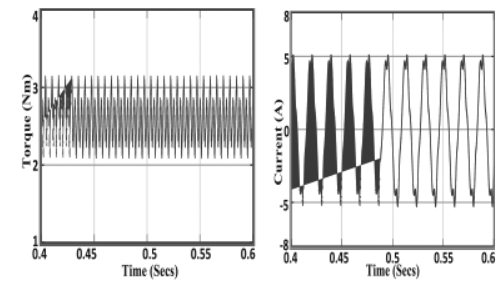

(a)

Figure 6 Torque and phase current at $2 \mathrm{kHz}$ for (a) PMMPC
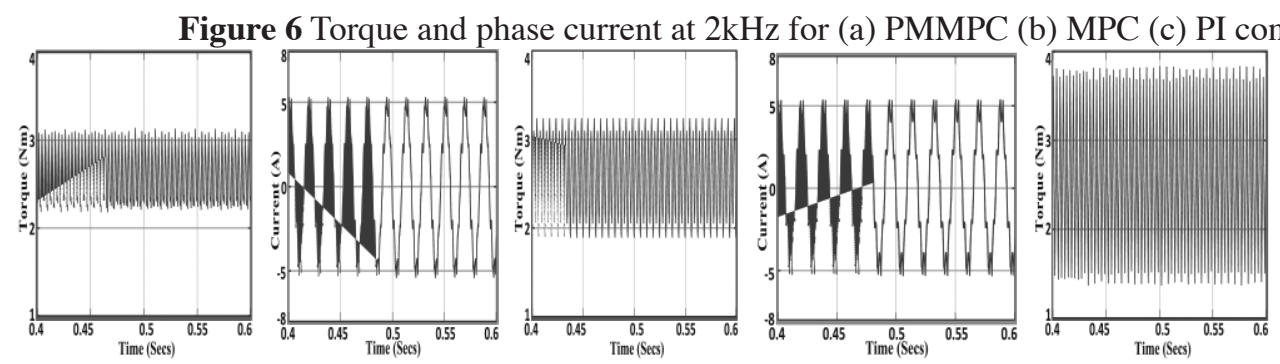

(c)
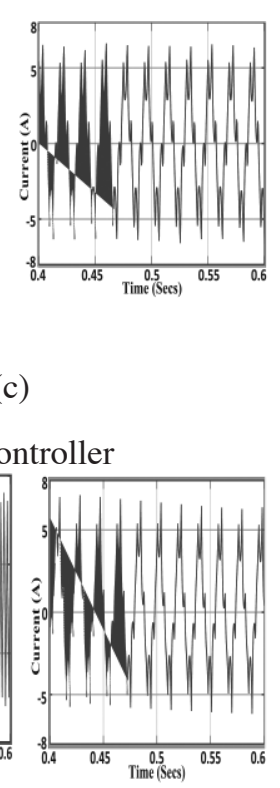

(a)

(b) (c) 


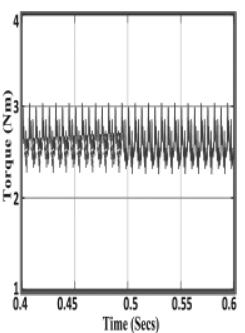

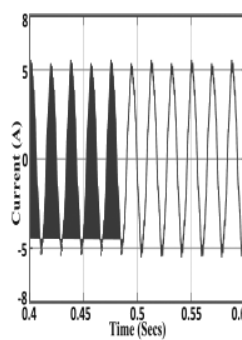

(a)

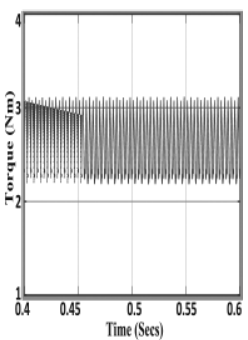

(b)

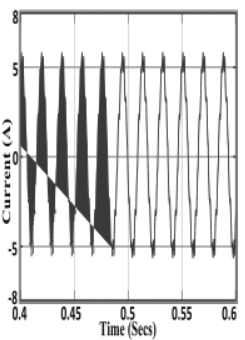

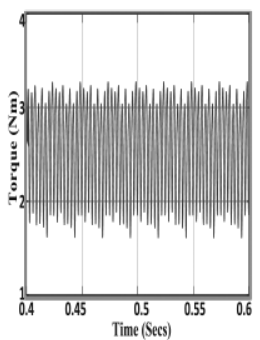

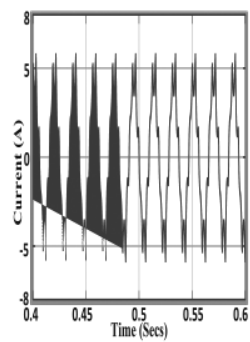

(c)

Figure 8. Torque and phase current at 8kHz for (a) PMMPC (b) MPC (c) PI controller

\section{EXPERIMENTAL RESULTS}

The proposed method is tested and verified with the help of prototype hardware setup. The model predictive control algorithm is applied in dSPACE DS 1106 and PWM control algorithm is applied in dSPACE DS 5203 board. The generated switching pulses are fed to the driver

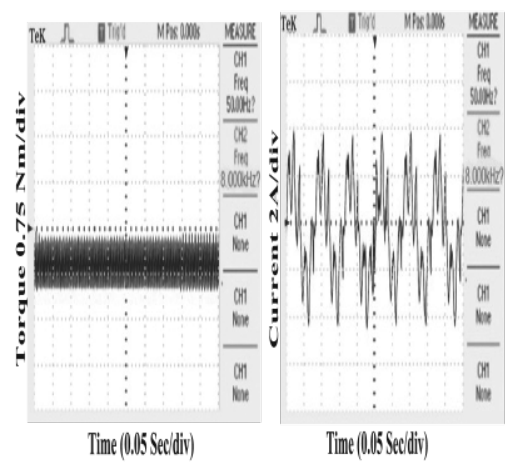

(a)

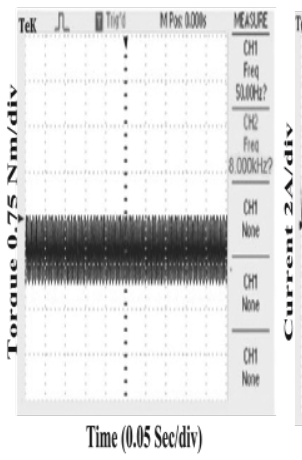

(b)

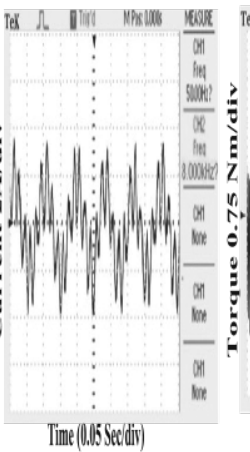

Time(1).5S Sediri)

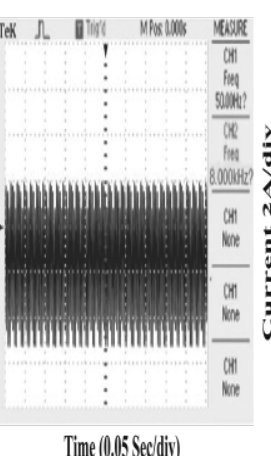

Time (0.05 Seeddiv)

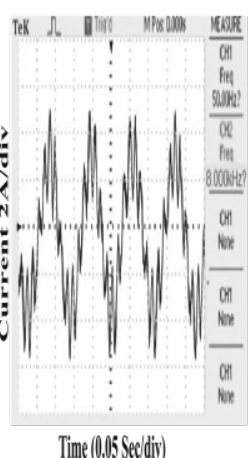

(c)

Figure 9. Experimental torque and phase current at $8 \mathrm{kHz}$ for (a) PMMPC (b) MPC (c) PI controller

Table 1. Torque ripple behaviour for different controller

\begin{tabular}{|c|c|c|c|c|c|c|}
\hline \multirow{2}{*}{ Switching frequency } & \multicolumn{3}{|c|}{$\begin{array}{c}\text { Simulation Results } \\
\text { Torque ripple (\%) }\end{array}$} & \multicolumn{3}{c|}{$\begin{array}{c}\text { Experimental Results } \\
\text { Torque ripple (\%) }\end{array}$} \\
\cline { 2 - 7 } & PMMPC & MPC & PI & PMMPC & MPC & PI \\
\hline $8 \mathrm{kHz}$ & 22 & 27 & 46 & 31 & 39 & 60 \\
\hline $4 \mathrm{kHz}$ & 29 & 42 & 63 & 38 & 55 & 75 \\
\hline $2 \mathrm{kHz}$ & 36 & 48 & 69 & 44 & 62 & 89 \\
\hline
\end{tabular}

circuit. A torque sensor has been used for the measurement of torque of BLDC motor system. 
All the experimental results are obtained with the help of digital storage oscilloscope. The torque ripple and current waveform have been obtained for different controller at switching frequency $2 \mathrm{kHz}, 4 \mathrm{kHz}, 8 \mathrm{kHz}$, as seen in figure 9. All the results are close to the simulation results. It has been observed that the torque ripple performance is improved while using proposed phase modulated model predictive control technique as compared to the model predictive control and proportional integral control techniques. Again, it is justified with software results. A comparative simulation and experimental analysis for different controller has shown at different switching frequency in Table 1. These experimental results are shown the efficient torque ripple performance of BLDC motor while using proposed phase modulated model predictive control technique.

\section{CONCLUSION}

A phase-modulated model predictive current control technique is proposed to reduce the torque ripple in BLDC motor. The output result of PMMPC is superior to the MPC and PI controller. The PMMPC has constant switching frequency due to inclusion of modulation technique which improves the torque ripple performance. Torque ripple performance is shown with PMMPC, MPC and PI current control strategy at different switching frequency. It has been noticed that the torque ripple performance is superior for PMMPC as compared to the MPC and PI control technique. It has also been found that the torque ripple will decrease if the switching frequency increases. The performance of stator current is much better in case of PMMPC as compared to the MPC and PI controller. The stator current has lower spikes in case of PMMPC, which improves the torque ripple. The experimental analysis has done to validate the simulation results and these experimental results are obtained close to simulation results.

\section{REFERENCES}

Shao, J. 2006. An Improved Microcontroller-Based Sensorless Brushless DC (BLDC) Motor Drive for Automotive Applications. IEEE Transactions on Industry Applications. 42 (5): 1216-1221.

Cui, C., Liu, G. \& Wang, K. 2015. A Novel Drive Method for High-Speed Brushless DC Motor Operating in a Wide Range. IEEE Transactions on Power Electronics, 30 (90): 4998-5008.

Kim, H., Park, J. \& Hur, J. 2015. Comparison Analysis of Demagnetization and Torque Ripple in Accordance with Freewheeling Current in PM BLDC Motor. IEEE Transactions on Magnetics 51 (11): 1-4.

Viswanathan, V. \& Jeevananthan, S. 2015. Approach for torque ripple reduction for brushless DC motor based on three-level neutral-point-clamped inverter with DC-DC converter. IET Power Electronics. 8 (1): 47-55.

Krishnan, G. \& Ajmal, K.T. 2014. A neoteric method based on PWM ON PWM scheme with buck converter for torque ripple minimization in BLDC drive. Annual International Conference on Emerging Research Areas: Magnetics, Machines and Drives (AICERA/iCMMD), Kottayam. 1-6.

Viswanathan, V. \& Seenithangom, J. 2018. Commutation Torque Ripple Reduction in the BLDC Motor Using Modified SEPIC and Three-Level NPC Inverter. IEEE Transactions on Power Electronics. 33 (1): 535-546.

Doss, M. A., Premkumar, E., Kumar, G. R. \& Hussain, J. 2013. Harmonics and torque ripple reduction of Brushless DC motor (BLDCM) using Cascaded H-Bridge multilevel inverter. International Conference on Power, Energy and Control (ICPEC), Sri Rangalatchum Dindigul. 296-299

Viswanathan, V.\& Jeevananthan, S. 2017. Hybrid converter topology for reducing torque ripple of BLDC motor. IET Power Electronics. 10 (12): 1572-1587.

Baszynski, M. \& Pirog, S. 2018. Unipolar Modulation for a BLDC Motor With Simultaneously Switching of Two Transistors With Closed Loop Control for Four-Quadrant Operation. IEEE Transactions on Industrial Informatics.14(1): 146-155. 
Lad, C. K. \& Chudamani, R. 2018. Simple overlap angle control strategy for commutation torque ripple minimisation in BLDC motor drive. IET Electric Power Applications 12, (6): 797-807.

Lee, Y. 2019. Commutation Torque Ripple Minimization for Three Phase BLDC Motor Drive using A Simple PWM Scheme Reliable to Motor Parameter Variation. IEEE PES Asia-Pacific Power and Energy Engineering Conference (APPEEC), Macao, Macao. 1-4.

Ozturk, S. B. \& Toliyat, H. A. 2011. Direct Torque and Indirect Flux Control of Brushless DC Motor. IEEE/ASME Transactions on Mechatronics. 16 (2): 351-360.

Sarkar, P., Hazra, A. \& Mondal, A. 2020. A unified approach for PI controller design in delta domain for indirect field-oriented control of induction motor drive. Journal of Engg. Research. 8(3): 118-134.

Irum, M., Shahzad, M. \& Muhammad, E. 2020. Fuzzy Logic Based Time Series Prediction Algorithm Using Nearest Neighborhood Clustering. Journal of Engg. Research. 8(3): 135-152.

Song, J.H. \& Choy, I. 2004. Commutation torque ripple reduction in brushless DC motor drives using a single DC current sensor. IEEE Transactions on Power Electronics. 19 (2): 312-319.

Boroujeni, M.S., Markadeh, G.A. \& Soltani, J. 2017. Adaptive Input-output feedback linearization control of Brushless DC Motor with arbitrary current reference using Voltage Source Inverter. 8th Power Electronics, Drive Systems \& Technologies Conference (PEDSTC), Mashhad. 537-542.

Yaya, S. \& Honghua, W. 2009. Research on Reduction of Commutation Torque Ripple in Brushless DC Motor Drives Based on Fuzzy Logic Control. International Conference on Computational Intelligence and Security, Beijing. 240-243.

Manikandan, R. Arulmoziyal, R. \& Priyadharsini, K. R. 2013. Fuzzy PI based speed sensorless speed control of position sensorless BLDC drive. IET Chennai Fourth International Conference on Sustainable Energy and Intelligent Systems (SEISCON), Chennai. 57-64.

Liu, X., Wang, D. \& Peng, Z. 2019. Cascade-Free Fuzzy Finite-Control-Set Model Predictive Control for Nested Neutral Point-Clamped Converters With Low Switching Frequency. IEEE Transactions on Control Systems Technology, 27 (5): 2237-2244.

Vasiladiotis, M., Christe, A. \& Geyer, T. 2019. Model Predictive Pulse Pattern Control for Modular Multilevel Converters. IEEE Transactions on Industrial Electronics, 66 (3): 2423-2431.

Rodriguez-Bernuz, J. \& Junyent-Ferré, A. 2020. Operating Region Extension of a Modular Multilevel Converter Using Model Predictive Control: A Single-Phase Analysis. IEEE Transactions on Power Delivery. 35 (1): 171-182. Lei, M., et al. 2020. Full Degree of Freedom Based Control Scheme of the Single-Phase Direct AC-AC Modular Multilevel Converter for Railway Power Conditioning Under Asymmetric Branch Conditions. IEEE Transactions on Industrial Electronics, 67 (3): 1671-1683.

Jaiswal, R., Agarwal, A. \& Negi, R. 2019. Performance Enhancement of Modular Multilevel Converter by using Modulation Technique. IEEE 1st International Conference on Energy, Systems and Information Processing (ICESIP), Chennai, India. 1-6.

Li, J., Konstantinou, G., Wickramasinghe, H. R., Townsend, C. D. \& Pou, J. 2020. Capacitor Voltage Reduction in Modular Multilevel Converters Under Grid Voltages Unbalances. IEEE Transactions on Power Delivery. 35 (1): 160-170

Dekka, A., Wu, B., Yaramasu, V., Fuentes, R. L. \& Zargari, N. R. 2019. Model Predictive Control of High-Power Modular Multilevel Converters-An Overview. IEEE Journal of Emerging and Selected Topics in Power Electronics.7 (1): 168-183. 
Abdelkader, L., Krim, F. \& Borni, A. 2019. Model predictive control for an SAPF interfaced by a wind energy conversion system based on permanent magnet synchronous generator. Journal of Engg. Research. 7(1):1-19.

Zarei, M. E., Ramírez, D., Nicolas, C. V. \& Arribas, J. R. 2020. Three-Phase Four-Switch Converter for SPMS Generators Based on Model Predictive Current Control for Wave Energy Applications. IEEE Transactions on Power Electronics. 35 (1): 289-302.

Mahmoudi, H., Aleenejad, M. \& Ahmadi, R. 2017. A New Multiobjective Modulated Model Predictive Control Method With Adaptive Objective Prioritization. IEEE Transactions on Industry Applications. 53 (2): 1188-1199.

Tarisciotti, L., Zanchetta, P., Watson, A., Bifaretti, S. \& Clare, J. C. 2014. Modulated Model Predictive Control for a Seven-Level Cascaded H-Bridge Back-to-Back Converter. IEEE Transactions on Industrial Electronics. 61 (10): 5375-5383. 